\title{
Research on countermeasures of the contemporary college students in their interpersonal communication
}

\author{
Na Wang ${ }^{1, a, *}$ \\ ${ }^{1}$ The school of mechatronic engineering, Southwest Petroleum University, \\ Chengdu, 611130. P. R. China \\ aemail:318520405@qq.com
}

Keywords: College students, Countermeasures, Interpersonal communication

\begin{abstract}
With the rapid development of social economy, the interpersonal skills, as an important part of the personal comprehensive quality, plays a crucial role in a person's growth and development, and even become the major standard of one's ability. Our society needs a great number of people who have the spirit of teamwork and good interpersonal skills. The key to cultivate international talents is to establish a harmonious interpersonal relationship. Concentrating on the research of the present situation and reasons of the college students' interpersonal communication and how to build a harmonious college students' interpersonal relationship, this paper expounds the definition of interpersonal communication, the importance of college students' interpersonal communication and the principles and methods of establishing good interpersonal communication, and furthermore makes a comprehensive analysis of the present situation of the college students' interpersonal communication and puts forward the corresponding suggestions and countermeasures.
\end{abstract}

\section{Introduction}

The college students' interpersonal communication is a relationship between college students and others in the process of daily leaning, working or living. It mainly contains the relationship among families, the relationship between teachers and students, the relationship among classmates and friends or others[1]. Li Honghan and Zhao Chonglian think that college students' interpersonal relationship has broad and narrow meanings. For the broad meaning, it refers to the interpersonal relationship between the college students and all the related people, including families, friends and others. For the narrow meaning, it refers to the interpersonal relationship between them and the related groups and individuals in the university, especially for the relationship among teachers and students and classmates. Maslow's hierarchy of needs theory involves five basic needs. And those needs involve interpersonal category, which are adscription and love, respect and self-actualization, as shown in figure 1.

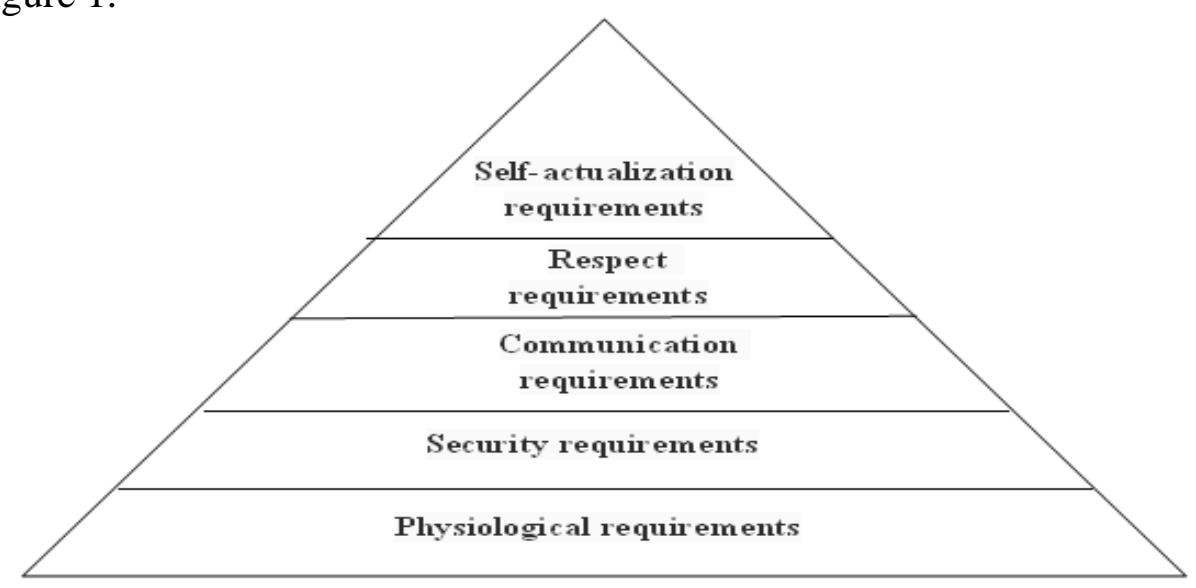

Fig.1 Maslow's hierarchy of needs theory

Generally speaking, interpersonal communication refers to the psychological distance or behavior individual and individual or individual and others. It reflects the psychological state of the individual 
or group to meet the social demand. In fact, this concept is not frequently used in sociology and psychology in the west. Western professors prefer to use some clearer concept, such as interaction, communication, interpersonal attraction, interpersonal conflict or social exchange and so on[2]. In Maslow's opinion, self-actualization is that a person tries one' $s$ best to become the one he could be. Anyone who can complete self-actualization is mind-open, cheerful, independent and creative, and they know what they need and who they are and what their missions are. Both these needs can be accomplished with the very good implementation.

\section{The type of the college students' interpersonal relationship}

(1) According to the scope of communication, it can be divided into three categories. They are the relationship between individual and individual, such as the relationship of classmates, friends, teachers and students and parents and children, the relationship between individual and group, such as the relationship between individual and one' $\mathrm{s}$ family and the same with students and classes and the relationship between group and group, such as the relation between class and class. According to the classification of the sociology, interpersonal relationship is divided into kinship and geographical relation and industry relations. Kinship refers to the relationship between parents and children, and the derivative of the relationship between brothers and sisters and other relatives. At present, we pay enough attention to the parents' educational mode, especially the family ties. Geopolitical relation refers to the interpersonal relationships in a public living area, such as peer relationship. Because a common place, a similar way of life, the same language and culture can bring more psychological compatibility. Industry relation is a common cause, forming a love relationship, such as the relationship between teachers and students, mentoring relationship.

(2) The primary type of the college students' interpersonal relationship[3].The relationship between teachers and students. Teachers and students are the two basic main bodies in college campus. Whether the relation between teachers and students is good or bad has a direct influence on the colleges' study and growth and determines whether the university can meet the students' social influence of physiological and psychological needs. The teacher, as a righteous person and a model for students, is an important object of college students' interpersonal communication. The equal communication between teachers and students helps them learn more and communicate well. The relationship between teachers and students, full of love, is the consequence of high compatibility between them. It is pure and self-giving. However, lacking of university classroom teaching interaction, teachers and students communicate few. Therefore, it is necessary to expand the emotional communication between teachers and students. The relationship between the college students is the basic interpersonal relationship. Classmates relation in the campus has a familial tendency, namely, it tends to create a stable, harmonious family for learning.

\section{The methods of the good interpersonal relationship of college students}

College students need to exercise themselves from all aspects, overcome various psychological problems, improve the interpersonal relationship and make themselves to adapt to college life better. In addition, owing to the severe employment situation, we must emphasis on interpersonal relations and master the reasonable mode of communication. As shown in figure 2, accumulating interaction experience becomes the need of the college students' real life and is also the essential condition of college students' to succeed.

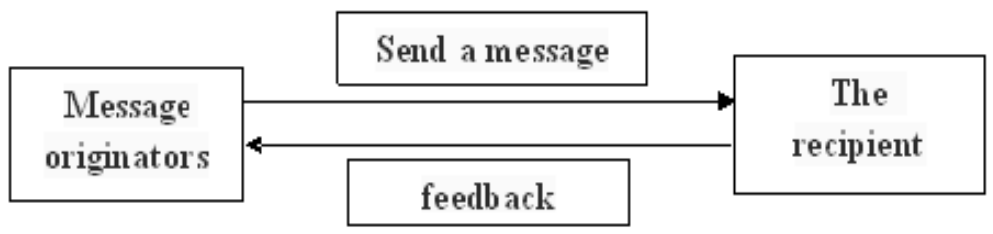

Fig.2 The reasonable mode of communication 
(1)To develop college students' good ideological quality and psychological quality

Good ideological quality often is reflected in the abilities of knowing themselves objectively, knowing other people, and understanding their relations with others and having strong psychological ability to resist setback, and so on[4]. People can truly know themselves according to society to make self education and to continue to anatomy and self-reflection, revising, play their own advantages, and overcome the disadvantages. The psychological quality is an important factor in determining the quality of relationships. We should improve the psychological quality of college students, improve the bear setbacks and deal with psychological crisis and overcome their character flaws. Most college students have a poor psychological tendency of self-righteous. They don't want to listen to others. And the sense of inferiority is another problem. They are timid, indifferent and lack of confidence in the future.

So it is necessary to adopt various methods to guide college students to maintain their psychological balance.

(2)To strengthen college students' interpersonal skills

The communication of college students generally limited in school and the family circle. The usual communication is limited to relatively simple students and teachers, classmates or friends who makes few conflicts or easily to forgive or be forgiven. Because college students focus on schoolwork, rarely communicate with people deliberately, and they cannot effectively deal with interpersonal conflict, so college students should learn some basic communication skills to communicate well with others. Poor interpersonal skills would cause interpersonal tension.

College students should be encouraged to engage boldly, timely improvement, and establish a positive and healthy relationship.

(3)To improve college students' network self-discipline consciousness

Network not only opens a world window for the college students and provides a large number of rich information resources, but also has a lot of negative effects. Many students indulge in the network and make virtual communication on the Internet. They are isolate and lack of real interpersonal to with others. Therefore, we should strengthen college students' network moral education, improve their sense of self-discipline and pay attention to the role of network in the communication of ideological and political education. We should take it as a new channel new form and new carrier of the ideological and political work in the new position, attach great importance to the network communication of the hidden value, emphasize on the correct guidance of public opinion ideological and political education and play a part in the propaganda and ideological education.

\section{The principles of college students' interpersonal communication}

(1)Equality. During the process of interpersonal communication, we need to pay something or meet certain requirements. So the degree of interaction and inputs must be equal and equality is the premise to build relationships. The interpersonal communication in the psychology is positive, mutual and reciprocal. People need love and respect and hope to be equal. The principle of equality is the basic principle in the modern civilized society. Only feel the respect of other people and society, can they feel the existence of self worth. Mutual respect and equality are the basic principles to promote interpersonal communication. When the colleges communicate with others, they have many differences, such as qualifications, skills, knowledge, etc.. But they are equal individuals in the interpersonal interaction and equality is the premise to establish a good relationship. Psychological research shows that people need friends and respected and the young students especially need friends and respected. They desire to be independent of the family and really exist in the society. In the university, because of different family environment, living habits, etc, there is a difference. Many colleges, who own a better conditions than others often feel they are superior, which is not benefit for the harmonious interpersonal relationship[5].

(2)Credibility. Credibility refers to the honest and trustworthy in the interpersonal communication. Without credit, interpersonal relationships cannot go deeper, maintain and develop. In the Confucian' s book, trust is to be honest. Integrity is one of China's traditional virtues and the basic 
requirement of modern society. First, the good faith is a standard for one to treat others and do things and also is an important principle to establish a good relationship with others. A society cannot depend on an individual to establish a complete social system, but has a good relationship. Moreover, good faith is beneficial to set up a harmonious interpersonal communication. From a moral sense, people pay more attention to the nature of human, emotion, quality, and ethical behavior. If both sides communicate based on the mutual trust, honesty and mutual understanding, they can found an equal and harmonious relation beyond age, status, gender, identity and social.

(3)The principle of seeking common ground while putting aside differences. In the process of interpersonal communication, there is more than one opinion. People conflict because of different views. If there are differences, seeking common ground while putting aside differences is the first principle to solve conflicts. Individuals should be strict with themselves, which reveals the importance of personal accomplishment. People should have the ability to tolerant others, put yourself in for the sake of each other, accept others, seek common ground while putting aside differences, and set up the positive and healthy state of mind. Only tolerate others, can we achieve harmony and common development.

(4)The principle of mutual benefit and win-win results. The principle of mutual benefit and win-win results refers to mutual respect and mutual benefit principle, help and care about each other. It is also the principle of market economy and human society. To be the first, basing on the actual conditions of contemporary college students, mutual reciprocity and mutual benefit are moral values consistent with market economy's. Market economy, in terms of its nature, is the allocation of resources and the contradiction of fair and efficiency. Mutual reciprocity and mutual benefit, as a means of credibility, is its inherent demand. Some basic spirits are indispensable in a market economy. Secondly, mutual reciprocity and mutual benefit which is a kind of team spirit, is consistent with our basic moral values. The socialist market economic system with the main body of public ownership also contains a variety of ownership economy. It needs a unified moral. Psychological research shows that people want to get compliments from others in social life. According to the principle of compensatory effect, in the interpersonal communication, the more they pay, the more people they help, the easier they can form a loving human atmosphere.

A person wanting to survive and develop in the human society, needs to establish a good relationship with others. Interpersonal communication is the normal psychological needs of human emotions. When it is harmonious, people feel balanced and comfortable. On the contrary, they feel anxious or loneliness when interpersonal dispute or conflict happen. The interpersonal process is shown in figure 3

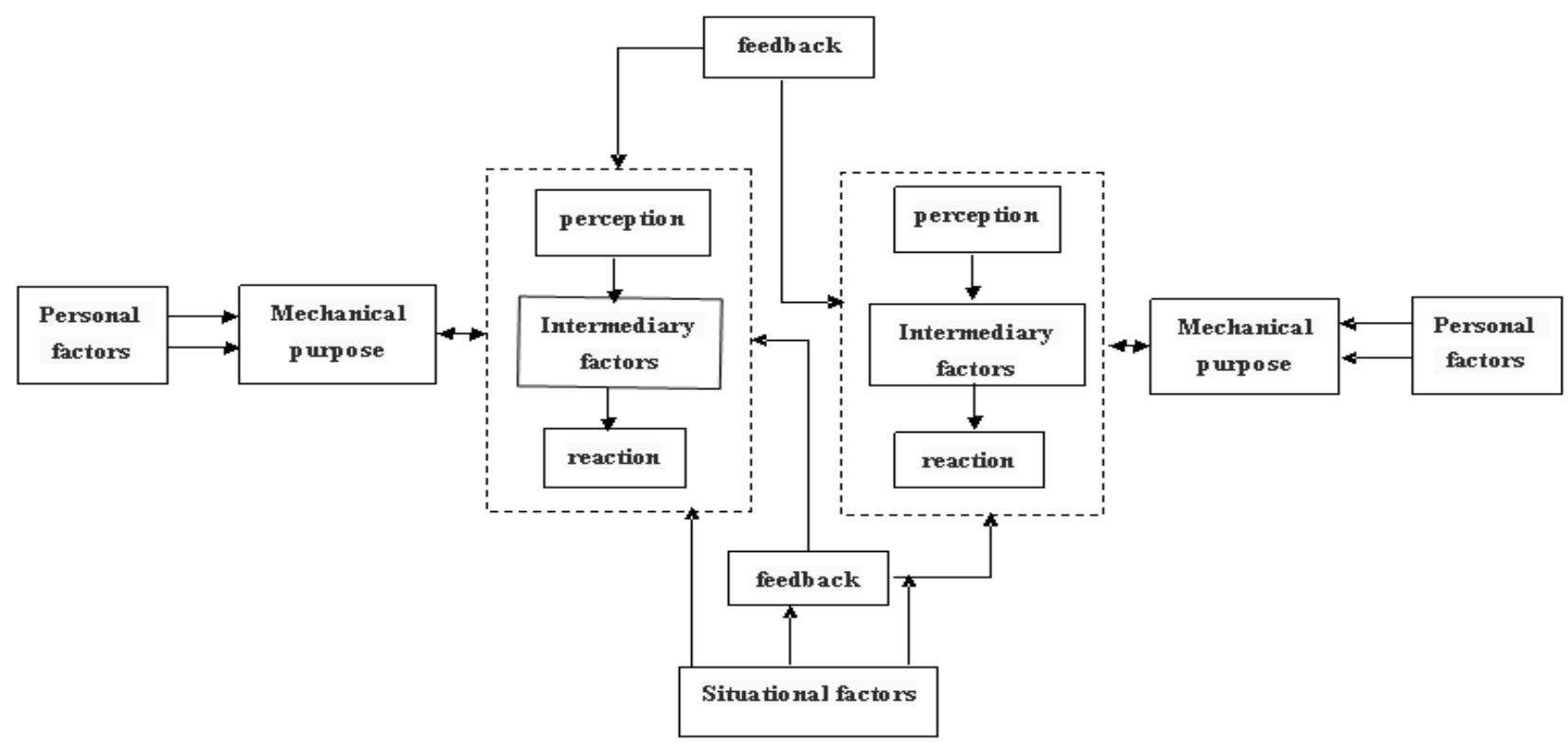

Fig.3 The interpersonal process 


\section{Conclusions}

This paper introduces college students' interpersonal interaction, expounds the concept of interpersonal interaction, the importance of college students' interpersonal interaction and the principles and methods to establish good interpersonal relationship. It also makes a comprehensive analysis of the present situation of the college students' interpersonal interaction and puts forward the corresponding suggestions and countermeasures. And it has a positive significance to put forward the countermeasures of improving college students' interpersonal interaction.

\section{References}

[1] H. H. Li, C. L. Zhao, College students' interpersonal relationships: based on the mental health, Journal of guangxi normal university.1(2004)116-121.

[2] X. Q. Tang, The problem of countermeasure analysis contemporary of college students interpersonal, The corpus of Science and education, (2009)37-39.

[3] X. Yu, The problem of college students' interpersonal relationship and countermeasures, Kaoshi weekly publication, (2010)12-15.

[4] J. K. Wang, Investigation of present situation of the contemporary college students interpersonal relationships. ,Journal of forefront Education,,vol. 91, No. 4(2008)30-31.

[5] X. Chen, Research on College students' mental crisis management, The adult education of China, (2005)16-18. 